\title{
Rheumatoid meningitis developed in patient with stable rheumatoid arthritis and myasthenia gravis-detailed analysis of intracranial inflammation using flow cytometry
}

Miki Oono ${ }^{1}$, Yoshimasa Fujita ${ }^{2}$, Nobuaki Uchida ${ }^{1}$, Ukichiro Kawai ${ }^{1}$, Michiyo Fujita-Nakata', Megumi Nakanishi' Mitsuru Sanada', Shigemi Nagayama ${ }^{1}$ and Makoto Matsui ${ }^{1 *}$

\begin{abstract}
Background: Rheumatoid meningitis (RM) is a rare disorder that often develops during a remission phase of rheumatoid arthritis (RA). This is the first study to demonstrate differences in regard to immunological disturbance between blood and cerebrospinal fluid (CSF) samples obtained from a patient with RM using flow cytometry.

Case presentation: A 36-year-old woman with RA and generalized myasthenia gravis (MG) developed RM during a remission phase. Although both RA and MG were stable and well controlled, she noticed fever, headache, and transient sensory disturbance. Blood and CSF examination findings suggested aseptic meningitis, while brain magnetic resonance imaging revealed restricted portions of meningitis and associated cortical lesions, compatible with a diagnosis of RM. The dose of oral prednisolone was increased, which ameliorated the symptoms within 1 week along with improvement in CSF findings. This patient exhibited features of RM that were manifested in a manner independent of the activity of RA. An investigation of cellular immunity using CSF specimens with flow cytometry showed differences in regard to the pathogenesis of inflammation in the CSF as compared to outside of the central nervous system. In contrast to results obtained with paired blood samples, CSF cells at the peak stage of RM showed a marked increase in CCR3 ${ }^{+}$Th2 cells and marked decrease in $\mathrm{CD}^{+}$cells, suggesting an immunoregulatory disturbance in the CSF. Those findings indicated a CSF-specific activation of humoral immunity, resulting in augmentation of meningeal inflammation, as shown by excess synthesis of intrathecal lgG and markedly elevated interleukin- 6 level. Results of the present detailed investigation of lymphocyte subsets revealed a discrepancy regarding the process of inflammation in this RM patient between CSF and blood samples.
\end{abstract}

Conclusions: RM is not a simple reflection of the immune status of RA, as the pathogenesis seems related to, at least in part, CSF-specific immunological dysregulation.

Keywords: Rheumatoid meningitis, Myasthenia gravis, Rheumatoid arthritis, Flow cytometry, Cerebrospinal fluid, Interleukin-6, Humoral immunity

\footnotetext{
* Correspondence: veritasm@kanazawa-med.ac.jp

'Department of Neurology, Kanazawa Medical University, 1-1 Daigaku,

Uchinada, Kahoku-gun, Ishikawa 920-0293, Japan

Full list of author information is available at the end of the article
}

(c) The Author(s). 2018 Open Access This article is distributed under the terms of the Creative Commons Attribution 4.0 International License (http://creativecommons.org/licenses/by/4.0/), which permits unrestricted use, distribution, and reproduction in any medium, provided you give appropriate credit to the original author(s) and the source, provide a link to the Creative Commons license, and indicate if changes were made. The Creative Commons Public Domain Dedication waiver (http://creativecommons.org/publicdomain/zero/1.0/) applies to the data made available in this article, unless otherwise stated. 


\section{Background}

Development of rheumatoid meningitis (RM), a rare autoimmune inflammatory disease of the central nervous system (CNS), is often seen in well-controlled rheumatoid arthritis (RA) patients [1, 2] or even manifested as the first symptom in patients with RA $[3,4]$. We treated a young woman diagnosed with myasthenia gravis (MG) and RA, who presented with meningitis and transient sensory disturbance during a remission phase of both disorders. A flow cytometry investigation of cellular immunity using cerebrospinal fluid (CSF) and blood samples showed differences in regard to the pathogenesis of inflammation in the CSF and outside of the CNS.

\section{Case presentation}

A 36-year-old woman with a 13-year history of generalized MG was diagnosed with RA 8 years prior to the present episode. The patient had undergone a thymectomy, and both diseases were stable with alternate-day administrations of prednisolone $(8 \mathrm{mg}$ ) and weekly doses of methotrexate (12 mg) until she exhibited new neurological complications. At the time of the initial visit, the patient reported a 10-day history of headache in the left parietal region and also had a moderate fever of $38{ }^{\circ} \mathrm{C}$. On the sixth day after developing the headache, a transient sensory disturbance (dysesthesia) over the right face developed and then spread to the right upper extremity for $30 \mathrm{~min}$, which recurred twice that day; thus, she came to us and also noted headache and fever but no pain in any joints. Neurological examination findings were negative for meningeal irritation signs, and there were no symptoms of MG including ptosis, diplopia, dysarthria, or weakness in the four extremities. Mental state, deep tendon reflexes, and coordination were normal, and there was no sensory disturbance. The patient had no past history of hypertension, diabetes, or smoking.

Routine laboratory tests revealed elevated C-reactive protein (CRP) (6.09 $\mathrm{mg} / \mathrm{dl}$, normal <0.3 $\mathrm{mg} / \mathrm{dl})$ and erythrocyte sedimentation rate (ESR) (56 $\mathrm{mm}$ in $1 \mathrm{~h}$, normal <3-11 mm), while white blood cells were normal (7980/ $\mathrm{ll}$, normal 3040-8720/ $\mu \mathrm{l}$; neutrophils, 76.8\%, normal 40-77\%; lymphocytes, $11.6 \%$, normal 16-44\%). Serum electrolytes, creatine, liver enzymes, and the coagulation system were also normal, while titers for anti-acetylcholine receptor (AChR) (12 nmol/l, normal $<0.2 \mathrm{nmol} / \mathrm{l})$ and anti-ribonucleoprotein (RNP) $(15 \mathrm{U} / \mathrm{ml}$, normal $<0.5 \mathrm{U} /$ $\mathrm{ml}$ ) antibodies were elevated, though to the same extent as seen in previous examinations. Complements, as well as cytoplasmic and perinuclear anti-neutrophil cytoplasmic antibodies, were normal. The CSF sample obtained at admission was lymphocytic (white cell count $19 / \mu$, normal $<5$, predominance of mononuclear cells) with elevated levels of protein $(57 \mathrm{mg} / \mathrm{dl}$, normal $15-45 \mathrm{mg} / \mathrm{dl})$ and IgG (7.0 mg/dl, normal $0.5-4.0 \mathrm{mg} / \mathrm{dl}$; IgG index 0.80 , normal $<0.7$ ) and a normal glucose level (51 mg/dl, normal 50-80; serum glucose $116 \mathrm{mg} / \mathrm{dl}$; CSF:serum ratio 0.81). The oligoclonal IgG band was positive (seven bands), and intrathecal IgG synthesis was elevated $(6.0 \mathrm{mg} /$ day, normal $<3.3$ according to previous report [5]). Furthermore, interleukin-6 (IL-6) was markedly elevated in the CSF (843 $\mathrm{pg} / \mathrm{ml}$, normal $<12.1 \mathrm{pg} / \mathrm{ml}$ according to previous report [6]). Other CSF examination results were negative, including polymerase chain reaction analysis for infectious agents (herpes simplex, varicella zoster, cytomegalovirus, tuberculosis), cultures for bacteria and acid-fast bacilli, India ink capsule staining, and cytology for malignant cells. Brain magnetic resonance imaging (MRI) using fluid-attenuated inversion recovery (FLAIR) and diffusion-weighted imaging (DWI) showed hyperintense lesions in the subarachnoid space over the left parietal lobe and cortex adjacent to the meningeal lesion (Fig. 1a, b). The meningeal lesion was enhanced by gadolinium (Gd) (Fig. 1c). Moreover, DWI revealed a spot lesion suggesting the presence of an ischemic lesion in the left parietal cortex (Fig. 1d). No abnormalities were seen in magnetic resonance angiogram findings.

\section{Flow cytometric analysis}

Flow cytometry examinations of blood and CSF samples were performed prior to giving additional treatment for RM, using previously described methods [7]. The CSF sample obtained at admission was characterized by a marked increase in clusters of differentiation (CD) 4-positive helper $\mathrm{T}$ cells and a decrease in CD8-positive $\mathrm{T}$ cells, with a markedly elevated CD4/8 ratio of 11.5 , whereas the blood sample showed only a moderate increase in $\mathrm{B}$ cells and normal CD4/8 ratio of 2.5 (Table 1). C-C chemokine receptor type 5 (CCR5) and $\mathrm{C}-\mathrm{X}-\mathrm{C}$ chemokine receptor type 3 (CXCR3) are characteristic molecules expressed by type 1 helper $\mathrm{T}$ (Th1) cells, while CCR3 and CCR4 are expressed by Th2 cells [8]. Furthermore, the CD29 antigen has been shown effective to define helper-inducer T cells [9]. We used monoclonal antibodies against those surface molecules to identify helper $\mathrm{T}$ cell subsets capable of propagating immune reaction. Our findings revealed that the same CSF sample showed a marked increase in CCR3-positive Th2 cells in contrast to a modest increase of such cells in paired blood samples shown in results obtained in our previous study of viral meningitis (Table 1) [10].

\section{Treatment and outcome}

On the basis of laboratory and MRI findings, a diagnosis of RM was made and oral prednisolone administration was increased to a total dose of $30 \mathrm{mg} /$ day, 
DWI
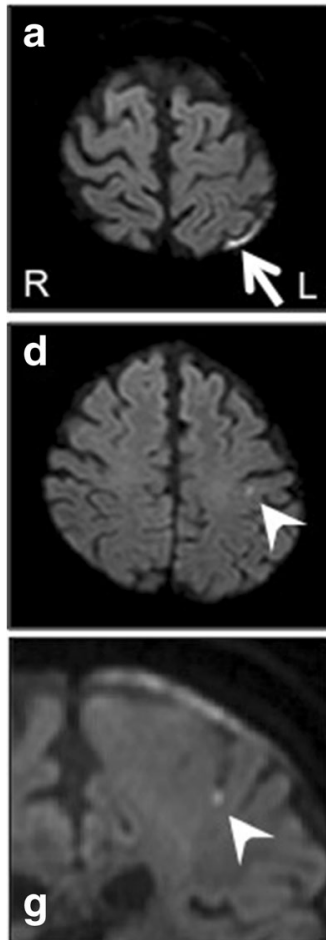

FLAIR
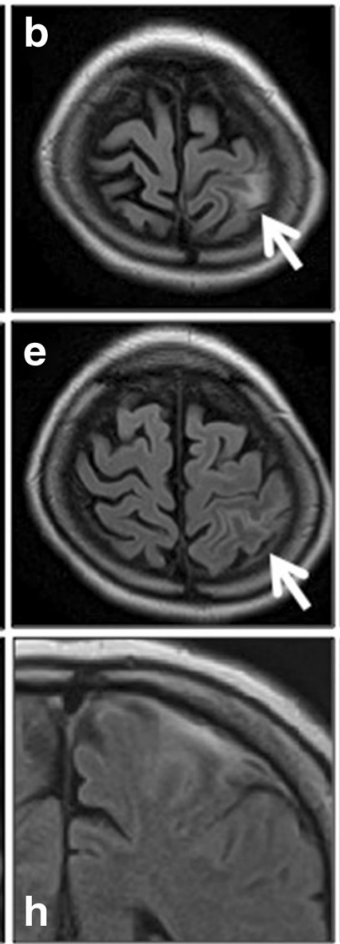

\section{Gd-enhanced T1WI}
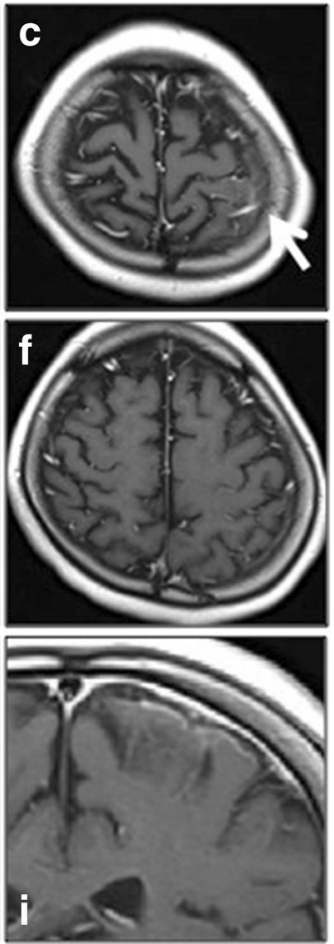

Fig. 1 Brain MRI scan findings at admission. a Axial DWI showing restriction of diffusion in the left temporal subarachnoid space (arrow). b, e Axial FLAIR images showing hyperintensity from the same lesion. $\mathbf{c}$, $\mathbf{f}$ Axial Gd-enhanced T1-weighted images showing partial enhancement in the left temporal subarachnoid space. $\mathbf{d}$ Axial DWI showing a spot lesion indicating restriction of diffusion in the left parietal cortex (arrowhead). g-i Coronal-DWI, FLAIR, and Gd-enhanced T1-weighted views of the same lesion shown in $\mathbf{d}$, e, and $\mathbf{f}$. DWI diffusion-weighted imaging, FLAIR fluid-attenuated inversion recovery, Gd gadolinium

while that of methotrexate was discontinued. Two days later, the fever and headache were ameliorated, followed by improvements in laboratory data, including CRP, ESR, and CSF cell count $(12 / \mu \mathrm{l})$, as well as levels of protein $(35 \mathrm{mg} / \mathrm{dl})$ and IL-6 $(3.4 \mathrm{pg} / \mathrm{ml})$ in the CSF (Fig. 2). After 3 months, the dose of oral prednisolone was tapered to $15 \mathrm{mg} /$ day and weekly methotrexate at $8 \mathrm{mg}$ was re-started. Brain MRI findings remained for 7 months, though without manifestation of neurological symptoms or signs.

Table 1 Lymphocyte subsets in blood and CSF samples obtained prior to treatment for rheumatoid meningitis

\begin{tabular}{llllll}
\hline Lymphocyte subset & Function & Blood (\%) & Viral meningitis & CSF (\%) & Viral meningitis \\
\hline CD3 & Mature T cell & 55.6 & $75.0 \pm 7.4$ & 88.8 & $86.7 \pm 8.7$ \\
CD4 & Helper T cell & 40.2 & $41.4 \pm 11.1$ & 81.5 & $66.3 \pm 10.2$ \\
CD8 & Suppressor/cytotoxic T cell & 16.2 & $33.0 \pm 14.3$ & 7.1 & $21.6 \pm 8.4$ \\
CD19 & B cell & 26.7 & $9.2 \pm 3.8$ & 3.8 & $3.7 \pm 6.5$ \\
CD3-CD16+CD56+ & NK cell & 18.9 & $13.9 \pm 6.6$ & 5.3 & $6.3 \pm 4.1$ \\
CD4+CD29+ & Helper-inducer T cell & 19.8 & $17.7 \pm 4.8$ & 69.2 & $47.7 \pm 12.2$ \\
CD4+CCR5+ & Th1 cell & 2.4 & $3.2 \pm 1.6$ & 21.4 & $16.3 \pm 13.3$ \\
CD4+CXCR3+ & Th1 cell & 8.7 & $11.7 \pm 3.7$ & 37.6 & $41.3 \pm 13.0$ \\
CD4+CCR3+ & Th2 cell & 11.4 & $1.4 \pm 1.7$ & 38.3 & $8.5 \pm 16.4$ \\
CD4+CCR4+ & Th2 cell & 1.3 & $3.1 \pm 2.5$ & 10.4 & $10.4 \pm 15.2$ \\
CD4/8 & & 2.50 & & 11.50 & \\
\hline
\end{tabular}

Values for viral meningitis were adopted from the results of a previous study, designated as [10] CSF cerebrospinal fluid, NK natural killer, Th1 type 1 helper T, Th2 type 2 helper T 


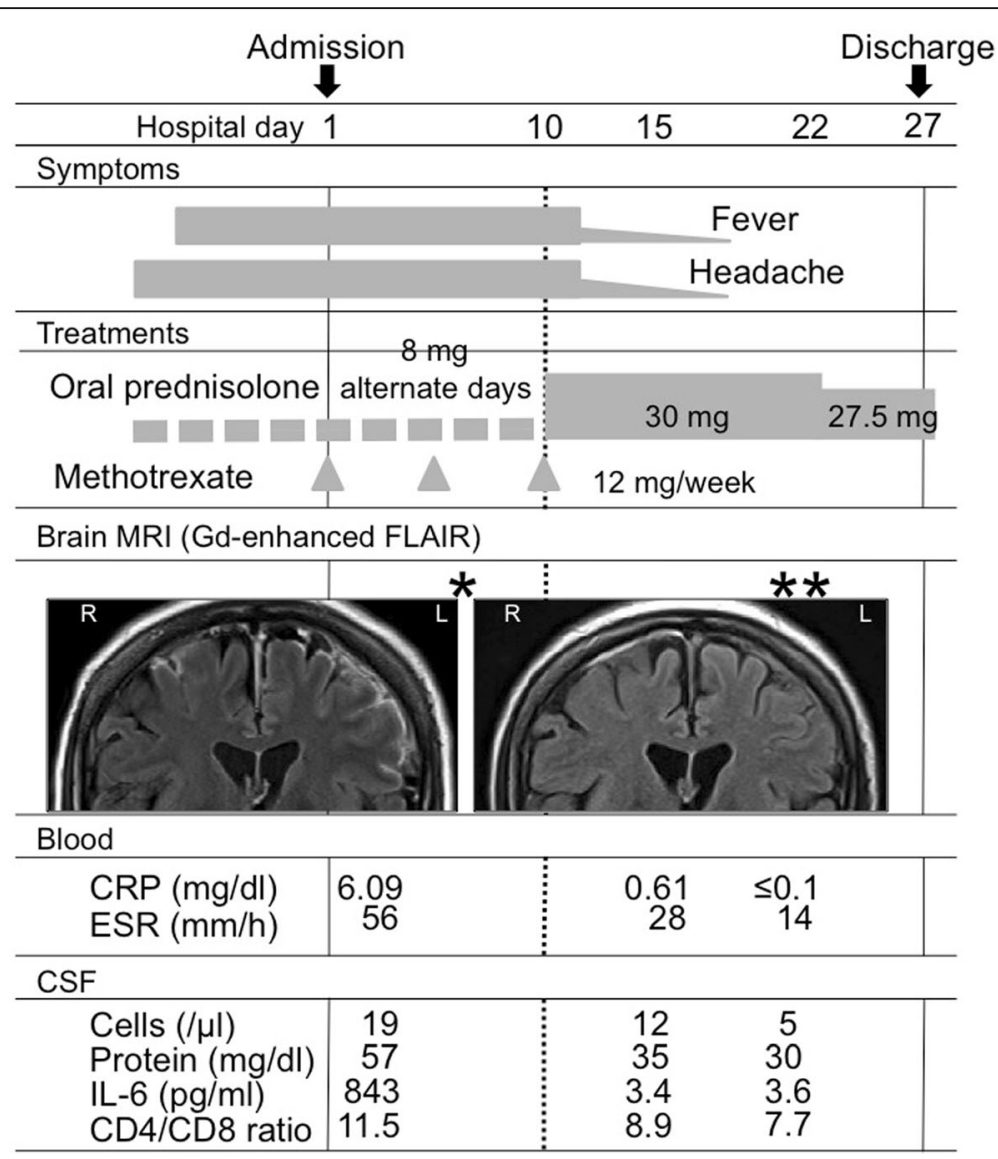

Fig. 2 Clinical course of the patient. Fever and headache rapidly improved after starting administration of oral prednisolone (30 mg/day). Coronal section images obtained with brain MRI and Gd-enhanced FLAIR revealed high intensity in the subarachnoid space in the bilateral parietal lobes (left dominant) (single asterisk). At 12 days after starting treatment, lesion size was reduced and high intensity in the cortex was decreased (double asterisks)

\section{Discussion and conclusions}

We treated a patient with RM who had a long history of MG and RA. This case showed reported features of RM, which were manifested independently of RA activity [1, 2], as well as neurological symptoms, including transient sensory disturbance [2, 11, 12]. Although most reported cases of RM include brain/meningeal biopsy findings, asymmetrical meningeal involvement revealed by MRI [1, 2, 6, 11-13] has been found helpful for an early diagnosis of RM, which contributes to improvement of treatment outcome [13, 14]. Indeed, some recent cases were diagnosed without biopsy findings, including the present $[3,6,15]$. The presence of vasculitis was reported in a biopsy specimen obtained from a case of RM [13], and cortical lesions likely develop as a consequence of impaired blood flow beneath the restricted area of inflammatory meningeal lesions. It is also conceivable that minor damage or ischemia in the cortex is manifested as transient ischemic attacks or seizure-like episodes. Furthermore, the fever noted in the present patient deserves mention, as this symptom has been reported only rarely even when the feeling of chills is included $[6,12,14]$. Interestingly, a previously reported patient with a fever of $38.2{ }^{\circ} \mathrm{C}$ [6] showed extremely high levels of IL- 6 in the CSF the same as the present patient, suggesting an ongoing intense inflammatory process in the CSF/meninges.

In the present case, it is noteworthy that RM developed during a phase of remission of both RA and generalized MG. If an extrinsic factor is present, such as an infectious event that can induce general $\mathrm{T}$ and/or $\mathrm{B}$ cell activation before development of RM, symptoms related to RA and MG will likely worsen along with elevation of immunological markers for those disorders. The good response of clinical symptoms, as well as improvement in ESR and CRP following administration of a moderate dose of corticosteroids alone in the present case and others [4], is similar to polymyalgia rheumatica. However, in our patient, no painful symptoms except for headache were noted during the entire course of illness. Instead, we found a marked increase in the CD4-positive helper $\mathrm{T}$ cell population, especially CCR3-positive Th2 cells, as well as marked decrease in CD8-positive cells in the CSF, in contrast to modest changes in those cells in 
blood. A subset of CD8-positive cells is known to have a role as suppressor $\mathrm{T}$ cells [16]; thus, we concluded that immunoregulation in the CSF was disturbed in the present case. Although B cells were increased along with a relative decrease in CD3-positive mature $T$ cells in blood as compared to the results of our previous study of viral meningitis and non-inflammatory neurological diseases [10], these findings may have been due to the effects of long-term immunosuppressive therapy with methotrexate. Furthermore, CSF samples showed an elevated IgG index, positive oligoclonal bands, and excessive intrathecal IgG synthesis. In light of the marked increase in Th2 cells in the CSF, these results indicate the presence of CSF-specific activation of humoral immunity resulting in propagation of meningeal inflammation, though the triggering factor or precise mechanism was not addressed in the present study. Another limitation is that we did not measure the level of IgG4 in serum. However, IgG4-related disease seems to be less likely in cases of asymmetric leptomeningitis [13].

In summary, we performed flow cytometric analysis of cellular immunity in a patient with RM, which showed that immunoregulatory disturbance associated with elevated Th2-type response in the CSF may have stimulated intrathecal IgG synthesis. Results obtained in this case indicate that the pathogenesis of RM differs from that of a systemic manifestation of RA and MG.

\begin{abstract}
Abbreviations
AChR: Acetylcholine receptor; ANCA: Anti-neutrophil cytoplasmic antibodies; CCR: C-C chemokine receptor; CD: Cluster of differentiation; CRP: C-reactive protein; CSF: Cerebrospinal fluid; DWI: Diffusion-weighted imaging; ESR: Erythrocyte sedimentation rate; FLAIR: Fluid-attenuated inversion recovery; Gd: Gadolinium; IL-6: Interleukin-6; MG: Myasthenia gravis; MRI: Magnetic resonance imaging; NK: Natural killer; RA: Rheumatoid arthritis; RM: Rheumatoid meningitis; RNP: Ribonucleoprotein; Th2: Type 2 helper T; TIA: Transient ischemic attack
\end{abstract}

\section{Funding}

This work was supported in part by a Health Labour Sciences Research grant for Rare and Intractable Diseases from the Ministry of Health, Labour and Welfare of Japan.

\section{Availability of data and materials}

The datasets used and analyzed for the current study are available from the corresponding author upon reasonable request.

\section{Authors' contributions}

MO was an attending physician responsible for treating the patient and provided major contributions for drafting the manuscript. YF was an attending physician involved in the assessment of patient status in regard to rheumatology. NU and UK performed the flow cytometry examinations of blood and CSF samples and analyzed those findings. MFN, MN, and SN were attending physicians involved in critical discussions concerning the activity of myasthenia gravis and severity of meningitis for improving treatment strategies. MS advised in regard to neurology in this case and provided major contributions for critical revisions of the manuscript. MM is a corresponding author and provided the concept for this case report as well as interpretation of immunological findings. All authors read and approved the final manuscript.

\section{Ethics approval and consent to participate}

This is a case report and has been granted an exemption from the Ethics Committee of Kanazawa Medical University. All procedures performed conformed to the provisions of the Declaration of Helsinki.

\section{Consent for publication}

Informed consent to publish the present case details and laboratory findings was obtained from the patient.

\section{Competing interests}

The authors declare that they have no competing interests.

\section{Publisher's Note}

Springer Nature remains neutral with regard to jurisdictional claims in published maps and institutional affiliations.

\section{Author details}

'Department of Neurology, Kanazawa Medical University, 1-1 Daigaku, Uchinada, Kahoku-gun, Ishikawa 920-0293, Japan. ${ }^{2}$ Department of Hematology and Immunology, Kanazawa Medical University, 1-1 Daigaku, Uchinada, Kahoku-gun, Ishikawa 920-0293, Japan.

Received: 6 March 2018 Accepted: 10 May 2018

Published online: 18 May 2018

References

1. Servioli MJ, Chugh C, Lee JM, Biller J. Rheumatoid meningitis. Front Neurol. 2011;2:84. Available from: https://journal.frontiersin.org/article/10.3389/fneur. 2011.00084/full.

2. Chowdhry V, Kumar N, Lachance DH, Salomao DR, Luthra HS. An unusual presentation of rheumatoid meningitis. J Neuroimaging. 2005;15:286-8. Available from: https://onlinelibrary.wiley.com/doi/abs/10.1111/j.1552-6569. 2005.tb00325.x.

3. Padjen I, Mayer M, Habek M, Kolenc D, Dotlić S. Redefining a diagnosis: from meningeal plasma cell granuloma to rheumatoid meningitis. Report of a patient follow-up. Neurol Sci. 2015;36:1047-8. Available from: https://link. springer.com/article/10.1007\%2Fs10072-015-2075-7.

4. Jessee R, Keenan RT. Rheumatoid arthritis presenting as rheumatoid meningitis: a case report. Case reports in internal medicine. 2017;4(3):17-20. Available from: https://doi.org/10.5430/crim.v4n3p17.

5. Tourtellotte WW, Ma BI. Multiple sclerosis: the blood-brain-barrier and the measurement of de novo central nervous system lgG synthesis. Neurology. 1978;28:76-83. Available from: http://n.neurology.org/content/neurology/28/ 9_Part_2/76.full.pdf.

6. Ikeda K, Takazawa T, Ito H, Ishikawa Y, Miura K, Yoshii Y, et al. Rheumatoid leptomeningitis: radiological alteration of cerebral hypoperfusion and subarachnoid lesions. Intern Med. 2010;49:1911-6. Available from: https:// www.jstage.jst.go.jp/article/internalmedicine/49/17/49_17_1911/_article.

7. Matsui M, Araya SI, Wang HY, Matsushima K, Saida T. Differences in systemic and central nervous system cellular immunity relevant to relapsingremitting multiple sclerosis. J Neurol. 2005;252:908-15. Available from: https://link.springer.com/article/10.1007\%2Fs00415-005-0778-z.

8. Bonecchi R, Bianchi G, Bordignon PP, D'Ambrosia D, Lang R, Borsatti A, et al. Differential expression of chemokine receptors and chemotactic responsiveness of type 1 T helper cells (Th1s) and Th2s. J Exp Med. 1998; 187:129-34. Available from: http://jem.rupress.org/content/187/1/129.long

9. Morimoto C, Letvin NL, Boyd AW, Hagan M, Brown HM, Kornacki MM, et al. The isolation and characterization of the human helper inducer $\mathrm{T}$ cell subset. J Immunol. 1985;134:3762-9. Available from: http://www.jimmunol. org/content/jimmunol/134/6/3762.full.pdf.

10. Nakata M. Useful laboratory parameters in blood and CSF for evaluation of pathological in patients with acute viral infection of the CNS. J Kanazawa Medical University. 2009:34:101-6.

11. Jones SE, Belsley NA, Mcloud TC, Mullins ME. Rheumatoid meningitis: radiologic and pathologic correlation. Am J Roentgenol. 2006;186:1181-3. Available from: https://www.ajronline.org/doi/pdf/10.2214/AJR.05.0859.

12. Cianfoni A, Falcone C, Faustini F, Lauriola L, Imbesi S, Marca GD, et al. Rheumatoid leptomeningitis: magnetic resonance imaging and pathologic findings-a case report. J Neuroimaging. 2010;20:192-4. Available from: https://onlinelibrary.wiley.com/doi/epdf/10.1111/j.1552-6569.2008.00299.x. 
13. Choi S-J, Park YH, Kim JA, Han JH, Choe G, Kim SY. Pearls \& oy-sters: asymmetric involvement is a common feature of rheumatoid meningitis Neurology. 88:e108-10. Available from https://doi.org/10.1212/WNL. 0000000000003744.

14. Lu L, Chwalisz B, Pfannl R, Narayanaswami P. Rheumatoid meningitis: a rare complication of rheumatoid arthritis. BMJ Case Rep. 2015. Available from: doi:https://doi.org/10.1136/bcr-2014-208745.

15. Hasiloglu Zl, Asik M, Erer B, Dikici AS, Altintas A, Albayram S. Magnetic resonance imaging of rheumatoid meningitis: a case report and literature review. Rheumatol Int. 2012;32:3679-81. Available from: https://ink.springer. com/content/pdf/10.1007\%2Fs00296-011-2105-6.pdf.

16. Morimoto C, Rudd CE, Letvin NL, Schlossman SF. A novel epitope of the LFA-1 antigen which can distinguish killer effector and suppressor cells in human CD8 cells. Nature. 1987;330:479-82. Available from: http://www. nature.com/articles/330479a0

Ready to submit your research? Choose BMC and benefit from:

- fast, convenient online submission

- thorough peer review by experienced researchers in your field

- rapid publication on acceptance

- support for research data, including large and complex data types

- gold Open Access which fosters wider collaboration and increased citations

- maximum visibility for your research: over $100 \mathrm{M}$ website views per year

At BMC, research is always in progress.

Learn more biomedcentral.com/submissions 